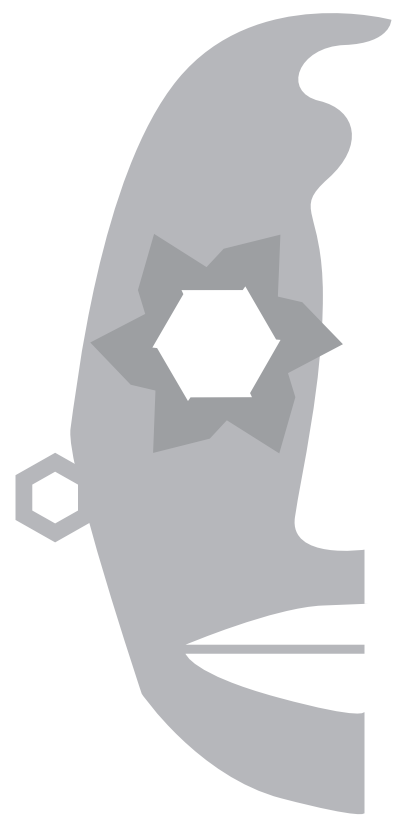

Thomas Rothe ${ }^{1}$

Universidad de Chile

Chile

\section{Relectura transcultural de un clásico revolucionario: Trágame tierra de Lizandro Chávez Alfaro}

\section{RESUMEN}

Aun cuando Trágame tierra ${ }^{2}$ (1969), de Lizandro Chávez Alfaro (1929-2006), es reconocida como la primera novela contemporánea nicaragüense, sigue ocupando un lugar marginal en el panorama de la crítica latinoamericana. Las lecturas que se le han hecho tienden a enfatizar cómo retrata los esfuerzos revolucionarios contra la dictadura somocista, dando poca importancia al elemento regional que Chávez Alfaro desarrolla, en particular el mundo cultural de la llamada Costa Atlántica. Este artículo analiza la novela a partir de una perspectiva transcultural, guiada por las elaboraciones teóricas de Ángel Rama, con el objetivo de problematizar cómo introduce la otredad cultural del Caribe nicaragüense en el discurso letrado nacional. Se centra en las diversas formas de representar el choque entre la modernización estatal y la diferencia cultural caribeña, en particular las representaciones de sujetos subalternos, la pluralidad de nombres y las tensiones presentadas entre la oralidad y la escritura. Se argumenta que estos elementos forman las piezas de una narrativa transculturadora que destaca la inherente conflictividad de toda simbiosis cultural.

Palabras clave: Trágame Tierra, Lizandro Chávez Alfaro, transculturación, Ángel Rama, Caribe nicaragüense

\footnotetext{
Abstract

Although Lizandro Chávez Alfaro's Trágame tierra (1969) is recognized as the first contemporary Nicaraguan novel, it remains marginal in the panorama of Latin American literary criticism. The few critical readings tend to emphasize its depiction of revolutionary efforts against the Somoza dictatorship, placing little importance on regional

1 Becario CONICYT.

2 Pese a que la obra se publica en 1969, para efectos de este artículo se utiliza la edición de 1971.
} 
elements, particularly the culture of the so-called Atlantic Coast. This article analyzes the novel from a transcultural perspective, as outlined by Ángel Rama, in order to discuss how the cultural otherness of Nicaragua's Caribbean coast creates friction in the national literary discourse. The paper focusses on different forms of representing the clash between State modernization and the Caribbean cultural difference through subaltern characters, the plurality of names, and tensions between orality and writing. These elements form the pieces of a transcultural narrative that stresses the inherent conflicts in cultural symbiosis.

Keywords: Trágame Tierra, Lizandro Chávez Alfaro, transculturation, Ángel Rama, Caribbean coast of Nicaragua

\section{Introducción}

Lizandro Chávez Alfaro es generalmente considerado el fundador de la narrativa nicaragüense contemporánea, elogio que ganó con su primera novela, Trágame tierra, publicada en México en $1969^{3}$. El hecho de que un autor nacido y crecido en Bluefields, capital de la actual Región Autónoma del Caribe Sur (RACS), llegue a ser innovador y representativo de la literatura nacional constituye una hazaña casi inverosímil en un país que ha marginado económica, política y culturalmente a dicha región. Para sumar paradojas, la novela goza más de renombre que de un corpus contundente de interpretaciones críticas, encajándola en un canon de literatura revolucionaria que limita las dimensiones de su alcance ${ }^{4}$. Este artículo analiza Trágame tierra (1971) guiado por las conceptualizaciones que Rama (2007) elabora en torno a la transculturación narrativa, con el objetivo de problematizar su discurso regionalista dentro del imaginario nacional nicaragüense de la segunda mitad del s. XX.

La novela de Chávez Alfaro ilustra el choque entre el proyecto modernizador estatal y la diferencia cultural de la región caribeña. La modernización que lleva a cabo el Estado nicaragüense a mediados del s. XX estuvo condicionada en gran medida por fuerzas políticas y económicas externas -principalmente estadounidenses- que reforzaron una estructura de colonialidad en el país, entendida como un patrón de dominación que empieza a configurarse con la Conquista de América que jerarquiza el poder en categorías raciales y geopolíticas (Quijano, 2000). Utilizando producciones culturales modernas, como la escritura y, especialmente, el género novelístico, Chávez Alfaro expone un tipo

3 Según el criterio de Ramírez (1973), Trágame tierra es "la primera novela centroamericana de ámbito universal" (p. 53); para Palacios (1991), "significó un salto cualitativo en la renovación de la novelística nicaragüense" (p. 1025); Mackenbach (2002) señala que es la "novela «fundadora» de la nueva novelística en Nicaragua" (p. 118); y Addis (2008) recuerda a Chávez Alfaro como el "fundador de la novela moderna nicaragüense" (p. 284).

4 Ríos Quesada (2016) advierte que la novela ha sido asociada con una literatura políticamente comprometida, que "ha caído en el olvido tanto del público como de la historiografía académica" (p. 196); y Delgado (2013/2014) señala que "La lectura de la novela es relativamente escasa, y poco abierta, hasta el presente, a nuevas interpretaciones" (p. 3). 
de modernidad a medias que ha dejado este proceso histórico. Aparte de distanciarse de ciertas técnicas narrativas tradicionales, como la linealidad o la claridad del narrador, Trágame tierra (1971) introduce el mundo cultural de la Costa caribeña nicaragüense con toda su otredad conflictiva para la identidad nacional indo-mestiza.

Mi lectura de la novela se centra en este problema de integración, donde se priorizan las representaciones del Caribe y los sujetos subalternos, la función dual de los nombres y las tensiones presentadas entre la oralidad y la escritura. Como argumento, estos ejes se entrecruzan para generar no solo una alegoría de la condición transcultural, sino también las piezas de una narrativa transculturadora.

\section{Enlaces transculturales}

El concepto de transculturación intenta explicar el fenómeno que se produce cuando dos o más culturas entran en contacto y generan un nuevo conjunto cultural, independiente pero arraigado en las culturas originales. En su uso original ${ }^{5}$, Ortiz (1987) busca tensionar la aplicación del término acculturation (aculturación), introducido por la antropología estadounidense durante las primeras décadas del s. XX, que implica un proceso de asimilación o deculturación por parte de una cultura subordinada. Aunque su emblemático Contrapunteo cubano del tabaco y el azúcar $(1940)^{6}$ hace poca referencia explícita al concepto, es ahí donde Ortiz (1987) vuelve a la historia cubana para demostrar la materialidad de los múltiples intercambios culturales en un contexto de desigualdad de poder. El mismo texto adopta un carácter genéricamente híbrido al unir recursos historiográficos, antropológicos y literarios, inscribiéndolo en la tradición del ensayismo de identidad latinoamericana, junto con Nuestra América (1891), el Ariel (1900), La raza cósmica (1925), Radiografía de la pampa (1933) e Insularismo (1939), entre muchos otros.

Rama (2007) retoma el concepto en $1982^{7}$ para comprender la producción literaria latinoamericana a partir de determinados ciclos modernizadores y valorar las respuestas creativas de escritores que negocian entre formas culturales propias y externas, entre la tradición y el desarrollo. Identifica en el esquema de Ortiz (1987) tres procesos fundamentales: pérdida, incorporación y reorganización, un cuadro que sin embargo no atiende suficientemente al

5 Ortiz utiliza el término por primera vez en el libro Contrapunteo cubano del tabaco y el azúcar (1940), cuya introducción de Bronislaw Malinowski constituye un texto emblemático en sí por su función legitimadora del neologismo. Ortiz conceptualiza la transculturación más explícitamente en su texto "Por la integración cubana de negros y blancos", también de 1940.

6 Para efectos de este artículo se usa la versión de 1987, pese a que la obra se publicó en 1940.

7 Para efectos de este artículo se utiliza la versión de 2007, aunque la obra se publicó por primera vez en 1982. 
aspecto de la selectividad, fundamental en toda cultura viviente. Partiendo de esta falta, Rama (2007) sistematiza su conceptualización en tres operaciones transculturadoras: primero, la lengua, que toma elementos del habla popular americana, influenciada principalmente por los idiomas indígenas; segundo, la estructuración literaria, que implica la incorporación de formas orales (flujo de conciencia o fragmentación de voces); y tercero, la cosmovisión, que es la capacidad de proyectar sistemas de creencia y pensamiento. Según el crítico uruguayo, la literatura que contiene estos tres niveles no solo responde más auténticamente a las realidades latinoamericanas, sino que restaura un modo regional de entender el universo que resiste el avasallador impacto de la modernización euro-occidental.

Señala Rama (2007): "nuestro propósito es registrar los exitosos esfuerzos de componer un discurso literario a partir de fuertes tradiciones propias mediante plásticas transculturaciones que no se rinden a la modernización sino que la utilizan para fines propios". Como se sabe, los escritores que logran realizar esta negociación serían los transculturadores, en oposición a la tradición cosmopolita de la ciudad letrada en América Latina. El análisis que ofrece Rama (2007) sobre las obras de Arguedas, Rulfo, Guimarães Rosa, García Márquez y Roa Bastos, demuestra un esfuerzo por visibilizar a varios autores ocultados por el boom latinoamericano, pese a la centralidad de García Márquez en dicho fenómeno. Aunque la obra de Chávez Alfaro cumple con varios requisitos transculturadores, no se incluye en este canon, lo que genera interrogantes sobre el porqué de esta situación: ¿se debe a un desconocimiento de la obra o a alguna razón más de contenido? ¿Acaso Chávez Alfaro no devuelve una significación interna (o costera caribeña en el caso nicaragüense) a su obra literaria?

Trágame tierra (1971) es una novela de corte histórico que, a través de 12 capítulos, entrega una visión de la realidad social, cultural y política en Nicaragua alrededor de 1950, en plena dictadura somocista. El referente histórico de fondo es Augusto César Sandino (1895-1934), cuya lucha contra la ocupación estadounidense durante las primeras décadas del s. XX lo transformó en una figura popular de resistencia nacional hasta la actualidad. La novela dialoga directamente con los procesos políticos del periodo, como la organización de las fuerzas opositoras del Frente Sandinista de Liberación Nacional (FSLN), que finalmente derrocarían a la dictadura en 1979, diez años después de la publicación de la novela. Al tomar en cuenta estos factores contextuales, Rodríguez (1985) afirma que "la novela venía a contribuir con una dimensión ideológica novel dentro de las letras nacionales", relacionada a "la voluntad de lucha" (p. 79). En este sentido, se podría ubicar a Chávez Alfaro dentro de lo que Gilman (2003) llama la familia 
intelectual latinoamericana, surgida de las redes internacionales en la época de los sesenta y setenta ${ }^{8}$. Aunque la lucha armada es un tema central en la novela, esta es compleja, tanto en lo temático como en lo estético, tomando distancia de la literatura de compromiso social.

También aborda otros fantasmas políticos que definen la historia del país, principalmente la ilusión de construir un canal interoceánico por el Río San Juan (discusión planteada desde las primeras décadas del s. XIX) y la integración de la llamada Costa Atlántica9 ${ }^{9}$, cuya composición cultural es más cercana al Caribe anglófono, con una importante presencia afrodescendiente y de indígenas misquito, además de poblaciones asiáticas y árabes. Con respecto a las tensiones entre ambos territorios del país, Delgado señala que "no hay un reconocimiento de lo caribeño como parte de lo nacional, ni tampoco las culturas del Caribe se ven representadas en las narrativas mestizas indo-hispánicas de la razón estatal-nacional" (2011, p. 66). En Trágame tierra (1971) esta región entra en primer plano, con paisajes que se colman de ríos, humedad, un sol deslumbrante y también flujos migratorios que muestran otras presencias y relaciones culturales.

Con una estructura polifónica la novela relata dos historias paralelas, cuyo hilo conductor es el conflicto generacional entre padres e hijos. La primera sigue la relación entre Plutarco Pineda y su hijo Luciano. Mientras Plutarco es un comerciante fluvial que cree en las virtudes del trabajo y defiende el statu quo, Luciano vive desafiando a su padre, desde cambiarse de nombre (bautizado Ronald) hasta unirse a las fuerzas guerrilleras para sublevarse contra la dictadura. Paralelamente, se narra la historia de Marcelo Barrantes y su hijo César, cuya ambigüedad sexual es el origen de varios conflictos familiares. César es ahijado de Plutarco y termina rellenando la ausencia dejada por Luciano en la familia Pineda, asumiendo a su vez ciertos atributos femeninos.

Ambos padres representan una generación más conservadora y complaciente con un país atravesado por la colonialidad y la dictadura, mientras los hijos cuestionan las estructuras que los oprimen. Pese a representar personajes de esperanza, ambos jóvenes terminan asesinados, Luciano por los gendarmes de una cárcel en Managua, y César por un oficial de la Guardia Nacional. Estas dos historias están encapsuladas por monólogos del "pueta descalzo", un personaje alegórico en el cual me detengo más adelante.

8 Aparte del posicionamiento político en su obra, Chávez Alfaro también participó en esta red latinoamericana, pues residió un largo tiempo en México, donde empezó su carrera literaria, y publicó en distintos países del continente, entre ellos Costa Rica y Cuba. Tras ser ganador del Premio Casa de las Américas en 1963 por su libro de cuentos Los monos de San Telmo, Chávez Alfaro estrechó lazos con la institución cubana, reflejado en sus colaboraciones en la revista Casa y una reedición cubana de Trágame tierra en 1971 para la colección La Honda.

9 Como señala Sollis (1989), en términos estrictamente geográficos, la noción de Costa Atlántica no es la más precisa, ya que la región no se limita a territorios costeros y bordea el mar Caribe, no el Atlántico. 


\section{Escenarios caribeños}

La Costa Atlántica nicaragüense, también conocida como la Mosquitia, constituye un territorio transfronterizo que ha sido disputado largamente por distintos poderes externos. Fue protectorado inglés desde el $\mathrm{s}$. XVII hasta mediados del XIX, cuando se traspasó a manos estadounidenses para la explotación de materias primas. En 1894, el entonces presidente Juan Manuel Zelaya trató de "reincorporar" la región al territorio nacional, abriendo las puertas para la colonización interna de mestizos provenientes de la Costa Pacífica del país (Sollis, 1989; Chávez Alfaro, 1981). Al consolidar su mando en 1937, Anastasio Somoza García facilitó la vuelta de las empresas estadounidenses, muchas dedicadas a la minería (Sollis, 1989). Se trata de una frontera imperial, para tomar prestada la noción que Bosch (2009) aplica al gran Caribe: una región intervenida por los intereses y las disputas extranjeras, que asientan las bases de industrias extractivas, sea la azucarera, la bananera o la mina.

Trágame tierra (1971) toma estos antecedentes históricos para construir una imagen compleja de la región caribeña. Plutarco Pineda, un colono mestizo proveniente de la Costa Pacífica, describe la región como una fuente de oportunidades, pero no sin insinuar el conflicto de su integración al resto del país:

La Mosquitia, todo un litoral esperándolos con su fisonomía de selva extranjera, tierra de promisión o palenque en el que todo era permitido; a veces hasta un acto de honestidad (...) Bluefields, Gray Town, Bragman's Bluff, Prinzapolka, Pearl Laggoon, Sandy Bay, eran nombres que alcanzaban el interior de la República con destellos de factorías tiradas en algún lugar de la costa del Caribe para que los nicaragüenses llegaran montadas en bueyes o en el botalón de una lancha, a reinar entre negros, indios y zambos que para la mayor diversión seguían considerándose súbditos de Eduardo VII, se resistían a hablar el español, y con un gesto despectivo nacido de la ascendencia inglesa a que se creían ligados por la historia, llamaban españoles a los otros indios, negros y mestizos que, armados de una mueca de conquistadores, emigraban de León, Nandaime, Totogalpa o Granada. (pp. 49-50)

Esta breve imagen resume el dilema nacional con respecto a la Costa Atlántica: parece un territorio extranjero, con su propia lengua e historia. Pero también revela que sus habitantes ("negros, indios y zambos") son en realidad como los demás nicaragüenses ("indios, negros y mestizos"), una representación que contrasta con el imaginario promovido por el discurso hegemónico nacional. Quizás el más conocido portavoz de ello es José Coronel Urtecho, cuya obra representa la costa caribeña como un paraíso inexplorado, bárbaro y caricaturesco, según hace ver Delgado: "Coronel restituye el punto de partida de la colonización, la promesa perpetua del territorio virgen, la posibilidad de una modernización «desde arriba» 
hecha a través de la inmigración [euro-occidental]" (2011, p. 69), una perspectiva donde "se puede percibir la arrogancia de la historia centralizadora que persigue el pionero-letrado y la lógica de dominación que sostiene su visión ${ }^{10 "}$ (2011, p. 71). Chávez Alfaro toma esta idea de la Costa caribeña como un destino de migración interna, pero sin exaltarla como un episodio heroico en la historia nacional, ya que la retrata como un territorio ya habitado, aunque culturalmente distinto. Al construir una genealogía de la colonialidad, supera las divisiones lingüísticas y culturales para demostrar las similitudes de ambas regiones, donde se enfatiza el compartido estatus subordinado de sus poblaciones. No obstante, la novela evita ofrecer resoluciones armónicas a la conflictiva historia nacional. Al contrario, destaca los distintos matices de las jerarquías sociales, raciales y genéricas, fortalecidas en un complejo entramado de colonización externa e interna.

La Mosquitia es un ejemplo de las regiones culturales que Rama (2007) describe a lo largo del continente, atravesadas por las fronteras de los Estados nacionales, en este caso entre Nicaragua y Honduras. Este aspecto geopolítico se aborda en la novela cuando Luciano llega a la frontera hondureña después de escapar de una emboscada de la Guardia Nacional. En el espacio fronterizo, descrito como un basural, Luciano imagina el lado hondureño, dibujando un paralelo con su propia vida:
Y más allá adivinaba las chozas húmedas, las pálidas excrecencias de la tierra donde el analfabeto duerme, come, cohabita junto a un arado de madera, con la punta guarnecida por la plancha de hierro que atestigua su último contacto con el tiempo. (p. 264)

Luciano comprende la miseria común de ambos pueblos, identifica la fragilidad de los límites territoriales del Estado. Es aquí, antes de ser capturado y devuelto como prisionero a Managua, cuando renuncia a la posibilidad de hacer la revolución, recuerda la aspiración social del padre y fantasea con seguir una ruta migratoria hacia el norte donde cumpliría el sueño americano. En medio de un flujo de conciencia, afirma: “(...) la principal tarea, la sustancia misma del carácter nacional era emigrar, lejos, lejos (...)" (p. 265); palabras que recuerdan a la conocida carta que Simón Bolívar envió al general Juan José Flores en 1830: "La única cosa que se puede hacer en América es emigrar" (2009, p. 387). Más que el sentido de desencanto que conecta a ambos revolucionarios separados por un siglo, sus conclusiones revelan cómo la migración vendría a integrar parte fundamental de la vida en América Latina y el Caribe, catalizada por guerras, dictaduras, economías de dependencia, colonialismo del pasado y del presente. No es de sorprender que, en la novela, la mayoría de los personajes de la costa caribeña están en constante movimiento o tengan una directa relación con los procesos migratorios. Sin ir más lejos, Luciano estudia en una escuela fuera de su

10 Delgado elabora su análisis a partir del libro Rápido tránsito: al ritmo norteamericano (1953). 
ciudad natal, después trabaja en la mina de Siuna, se une a las guerrilleras en las montañas del norte, luego es encarcelado en Managua, donde los gendarmes terminan matándolo. Un personaje que se construye a partir de un ritmo itinerante; Luciano solo vuelve al hogar muerto.

El vínculo entre migraciones e identidad caribeña se manifiesta de manera más clara en Víctor, un negro homosexual también llamado Viqui, quien es portador de la genealogía de migraciones afrocaribeñas hacia la región. Nieto de un obrero jamaiquino que había arribado a la costa nicaragüense en 1880, Víctor/Viqui mantiene viva la memoria de su abuelo a través de varios objetos en su casa: hay un daguerrotipo de la dinastía hannoveriana, que se contrasta con un retrato del abuelo, y un reloj de Liverpool, hecho de madera que "probablemente fuera fabricada por las propias manos del calafateador jamaicano que, desde la fotografía colgada en la pared opuesta, seguía contemplando su obra con altanería" (1971, p. 185). Estos escasos adornos demuestran la infiltración de las estructuras coloniales en los espacios privados, construyendo la identidad del abuelo como un "Fiel súbdito de la Reina Victoria" (1971, p. 93). Sin embargo, este linaje, que excluye las mujeres, termina con Víctor/Viqui, una "cepa estéril, expectante, enterrada en un yermo distante de todo" (1971, p. 94). Así, la narración evoca la memoria histórica de la población afrodescendiente y las rutas migratorias hacia la costa nicaragüense, pero no la continuación autónoma de su cultura en el territorio nacional donde predomina el español como mecanismo lingüístico unificador. Es revelador el hecho de que Víctor nunca habla en inglés criollo, siendo un personaje ya asimilado a los patrones culturales de la sociedad mayor. También es sugerente que no tiene apellido y no se revela el nombre del abuelo, lo que remite a la historia de deculturación que la estructura colonial y de plantación, efectuó sobre los africanos esclavizados a lo largo del Caribe (Fraginals, 1980).

El travestismo identitario de Víctor/Viqui claramente abre a una lectura de género que merece mayor análisis, pero que escapa a los propósitos de este trabajo. Lo destaco aquí para señalar un patrón narrativo de referirse a muchos de los personajes con dos o más nombres. Un caso de evidente tenor político lo constituye Anastasio Somoza García, o el Tacho en la vida real, nombres que no aparecen explícitamente en el texto, reemplazados por una serie de referencias, como Jefe Político, el cínico y mono amaestrado. No pronunciar el nombre del dictador refleja un ambiente de terror generalizado bajo su mando, levemente aliviado con los sobrenombres burlescos.

La doble identificación aparece con más protagonismo en Luciano, a quien sus padres nombraron Ronald. Aquí el acto de autoapodarse supera las dimensiones familiares de una rebeldía adolescente, entrando al plano de la toma de conciencia y posicionamiento político frente al alcance hegemónico de la cultura 
angloestadounidense en la Costa caribeña del país. Estas preocupaciones son implícitas a lo largo de la narración, pero emergen nítidamente al conocer a Chester P. Sánchez, un compañero de la guerrilla cuyo nombre genera sospechas: "Junto al infantil envanecimiento por el Chester estaba la $\mathrm{P}$, cercenada por un punto, y Luciano veía en ella el escamoteo de algo tan aberrante que había que velarlo: P de Philander o de Pontiac" (1971, p. 229). Chester cuenta que sus padres 1o llamaron así en honor al aviador estadounidense, Chester P. Latimer, quien los había salvado de una ofensiva sandinista en Puerto Cabezas (1971). Al escuchar la historia, Luciano exclama: "Y no te da vergüenza hijo de la gran puta tierra que te parió" (1971, p. 248), para luego reflexionar en voz alta: "Es mentira que sean inocentes; esos nombres. Es un adorno de bárbaros, la máscara que un bárbaro se pone para invocar el favor de un dios, o el nombre que una puta adopta en el burdel para agradar a los clientes" (1971 pp. 248-249). Aunque los demás compañeros no revelan el origen de sus nombres, siguen un patrón cultural anglo: Dennis y el mismo Ronald. En este sentido, los nombres sostienen las corrientes de un espectro colonial que cubre el país.

Otro caso significativo es el "pueta descalzo", cuyo nombre verdadero solo se revela al final de la novela, pero no sin cierta ambigüedad: "Tal vez si principio por acordarme de mi nombre. Me llamo Pan ... ¿cómo? Pánfilo... ¿cómo? ¿Tito? ¿Lino? Claro: Lino Cadenas. Me llamaba. Soy el pueta descalzo, ahora y para siempre $^{11 "}$ (1971, p. 418). La dualidad o la fluidez de los nombres puede leerse como característica de una condición transcultural, de estar en la encrucijada de varias fuerzas culturales, resultando en pérdidas, selecciones, incorporaciones y reintegraciones conscientes, como sostiene Rama sobre el concepto (2007). Esto a su vez evoca en la novela cierto estatus subordinado por el desorden y la multiplicidad de los significados que se asocia con países colonizados. De nuevo, el "pueta" opina: "Si pudiera nacerme me gustaría una ciudad tan grande y tan civilizada que no tuviera apodos" (1971, p. 225). Desprecia los apodos como un signo de la barbarie, pero, aun así, asume su propio apodo como una marca identitaria definitiva, una contradicción que revela la complejidad psicológica desprendida de la colonialidad.

Toda experiencia de colonialismo conlleva transformaciones lingüísticas, tanto en la lengua del colonizado como en la del colonizador, un fenómeno que Ortiz (1987) y Rama (2007) asocian con el proceso de transculturación, de los flujos bilaterales entre culturas, aunque con distintos niveles de influencia dependiendo de la posición de poder de cada una. En los países de la cuenca caribeña, los siglos de contacto cultural entre pueblos originarios, europeos, africanos y asiáticos, han producido una rica variedad de creoles que tienden a ser despreciados

11 De aquí en adelante, todas las citas de este personaje están en cursivas para respetar el estilo del texto original. 
frente a las lenguas estándares de cada contexto nacional. En el caso de Nicaragua, la situación de diglosia es justamente más notoria en la región caribeña, donde se habla al menos dos lenguas principales aparte del castellano: el inglés criollo y el miskito. Posterior al triunfo del sandinismo, Chávez Alfaro (1981) reconoce la importancia del factor lingüístico en su texto "Identidad y resistencia del 'criollo' en Nicaragua":

En la patria revolucionada que hoy tenemos es reconocido que son tres nuestras lenguas nacionales: el español, el miskito y el inglés criollo. Uno de los primeros y firmes pasos que se dieron en nuestro primer año de vida nueva fue la Cruzada de Alfabetización, cuya primera etapa se concluyó en español, se ha iniciado en miskito y está por empezar en inglés criollo; tarea esta última que ofrecerá mucho menos problemas numéricos, ya que por obra de las escuelas moravas, la población criolla es la de más bajo índice de analfabetismo. (p. 97)

Trágame tierra (1971), publicado más de una década antes de este texto, no explora la heterogeneidad lingüística a nivel estético y, de hecho, aparece escasamente como tema. Predomina una visión que defiende el uso del castellano como resistencia cultural ante la influencia del inglés, asociado al imperialismo de los militares y empresarios estadounidenses. Esta perspectiva se manifiesta en la esposa de Marcelo Barrantes, Carmela Obregón, cuyo conocimiento del inglés le ayuda a captar una clientela de oficiales estadounidenses para el negocio de su madre. Incapaz de afirmar una identidad nacional, sea de la tradición hispana centralizada o de la cultura anglocaribeña, Carmela utiliza el inglés para el beneficio económico personal y para marcar una diferencia en el estatus social. Así, cultiva una amistad con el empresario estadounidense, Thomas J. Hass, quien, a pesar de vivir más de un año en el país, no aprende hablar "la lengua nacional", entendida como el castellano (1971). De esta manera, la pluralidad de lenguas nacionales no entra en el discurso de la novela, más bien se reducen a la hegemonía de la tradición hispánica detrás de la identidad nacional.

Si por una parte el personaje de Luciano permite contemplar la organización de una revolución nacional que incluya el protagonismo de sujetos procedentes del Caribe nicaragüense, por otra parte, César Barrantes es una metáfora de la marginalización de la región caribeña: es malentendido por su familia (¿léase nación?) y, por lo tanto, enajenado, pero no rechazado por completo; mantiene vínculos con los Barrantes, quienes, hasta cierto punto se hacen cargo de él económicamente. En este sentido, la Costa Atlántica forma parte de Nicaragua como el hijo incomprendido que es César Barrantes. Es también sugerente que ambos jóvenes tienen personalidades plásticas, es decir, se adaptan bien a nuevas situaciones, lo que indica relación con el proceso de la transculturación. En César, esto se ve a través de su amistad con Víctor/Viqui, a pesar del castigo social que implica, y las 
tareas familiares que asume en la casa de su padrino, Plutarco. En Luciano, esta plasticidad surge al cuestionar los valores de sus padres, pero también al aceptar su derrota en la guerrilla. Al respecto, Rama (2007) señala que "Es el escritor quien ocupa el puesto de mediador, porque esa es su función primordial en el proceso, y es él quien devuelve al relato esa función mediante personajes que desempeñan dentro del texto esa tarea" (pp. 114-115). En el caso de los dos hijos en Trágame tierra (1971), la juventud vendría a representar las capacidades transculturadoras de poder integrar patrones culturales diferentes a sus vidas, pero no de una manera completamente armónica, ya que ambos mueren en el intento.

\section{Espejismos modernos}

Aunque la novela de Chávez Alfaro retrate una modernidad industrial en Nicaragua a mediados del s. XX, presente en imágenes como el tren, el telégrafo, la imprenta, las lanchas motorizadas e incluso la posible cibernética del futuro, también procura desenmascarar las contradicciones del modelo de modernización estatal. Este posicionamiento se evidencia desde el comienzo de la novela cuando Plutarco recuerda su antiguo trabajo de telegrafista. Debajo del "reloj de péndulo de bronce", que marca "ruidosamente cada segundo de molicie" y "el calendario japonés, bordeado de volutas azucaradas" (1971, p. 47), Plutarco lee un diario impreso en la capital hace tres días. La ironía de contrastar la tecnología que mide el tiempo con el atraso de las noticias ilustra la enorme distancia física y social que la modernidad estatal no puede acortar. La sensación de estar apartado del resto de la vida nacional, e incluso internacional, se intensifica para la región caribeña, cuyas diferencias geográficas y culturales obstaculizan la sincronización con la región centralizada de la Costa Pacífica. El "pueta descalzo" también expresa esta idea mediante sus fantasías de "nacer en otra parte" y seguir los cables del telégrafo para llegar a otras ciudades (1971, p. 224). El "hilito negro" que "a veces raya el cielo" compone una imagen donde la naturaleza se ve intervenida por la modernidad, que promete comunicación con el mundo exterior, pero donde finalmente "puede haber trampa en eso del hilo del telégrafo" (1971, pp. 224226). Estos signos de una modernidad a medias demuestran cómo los sujetos que habitan la región caribeña ocupan espacios subalternos en el orden nacional, al margen de los cambios acaecidos en el resto del país y en el mundo.

Existe en Trágame tierra (1971) otras maneras de criticar los proyectos modernizadores mediante recursos narrativos que bordean lo real maravilloso. La escena que mejor evoca elementos fantásticos empieza con una emboscada a los guerrilleros con quienes Luciano se ha unido. El combate se describe en términos confusos, a veces inexplicables, como cuando "Una de las figuras de cartón adquirió vida, levantó el brazo por encima de un trípode, apretó el gatillo de la ametralladora que tenía sobre la cabeza y volvió a quedar inmóvil" (1971, p. 252); 
episodios que quizás aluden a la incapacidad de comprender la extrema violencia de la guerra. Al huirse, Luciano cae en una pequeña cueva que lo atrapa en una posición fetal. Aquí imagina cómo sería

Fosilizarse para que un día -cien mil, trescientos mil años después- vinieran los solemnes curiosos de una nueva especie a descubrir el esqueleto, quizás hasta el hierro de un arma primitiva. Cuando ya no tuviera nombre, ni padre, ni madre, ni fecha y lugar de nacimiento. (p. 257)

La imaginada metamorfosis en una piedra anónima se relaciona con el destino de las civilizaciones mesoamericanas de antaño y su estudio arqueológico contemporáneo, lo que establece un vínculo directo entre el personaje y la historia de su tierra. Pero esta conexión rápidamente deja de ser política y cobra un sentido afectivo. Sujeto a un poder mayor que lo invade de angustia y espanto, Luciano siente "el amortiguado terror del brujo al pronunciar las palabras de conjuro" (1971, p. 259), llevándolo a criticar su propia ineptitud: "guerrillero que muere al esconderse en una cueva; la máquina de lo ridículo; vergüenza que engendra vergüenza (...) guerrillero que sale de nalgas" (1971, pp. 259-260). No queda absolutamente claro si Luciano conversa con una fuerza viva de la cueva o consigo mismo en una especie de monólogo interior, pero su evidente infantilización demuestra una entrega absoluta a la naturaleza. Hasta sus palabras pierden cierta sintaxis para transformarse en un lenguaje más crudo. De manera que la tierra se vuelve una figura maternal al acogerlo, pero no sin devolverlo al mundo con una lección. Este parto o renacimiento metafórico entrega una clave de la novela vinculada al título: "Trágame tierra" cobra sentido como una súplica desesperada e irónica, un suspiro de fatiga en la cuesta arriba contra el poder estatal que perpetúa la subordinación del pueblo nicaragüense bajo dictadura. Los hechos confusos y maravillosos de la secuencia en la cueva destacan la importancia de una relación vital con la tierra y tensionan la razón de una modernidad euro-occidental.

El conflicto entre sectores subalternos y aquellos que detentan el poder del Estado constituye un motivo recurrente en la literatura latinoamericana, generalmente en torno a la cuestión indígena. En novelas como El mundo es ancho y ajeno (1941) de Ciro Alegría, Hombres de maíz (1949) de Miguel Ángel Asturias y Todas las sangres (1964) de José María Arguedas, cada vez que los sujetos subalternos cuestionan estructuras sociales hegemónicas y salen de los marcos legales impuestos por el Estado, terminan criminalizados, encarcelados e incomunicados del resto de la sociedad. En Trágame tierra (1971), tanto Luciano como su padre son encarcelados, el primero por intentar sublevarse contra las fuerzas estatales y el segundo por simple afiliación paternal. El tiempo que pasa Plutarco Pineda en el calabozo revela al menos dos aspectos centrales del discurso narrativo. En primer lugar, los métodos de interrogación que la Guardia Nacional le aplica delatan el disfraz de la modernización desarrollista promovida por el gobierno dictatorial: 
Y lo siniestro radicaba en lo que cualquier mentalidad interesada en leer periódicos, por lo menos, hubiera descubierto a primera vista: aquel montón de objetos no era un «detector de mentiras», y en la medida del fraude debía esperarse brutalidad. Proporcional a lo burdo del engaño tendría que ser la manera de obligarlo a creer que aquella caja (desecho de algún aparato médico, probablemente) estaba registrando verdades y mentiras. (p. 172)

Paradójicamente, la supuesta tecnología usada para detectar mentiras es en sí una mentira. Para compensar la farsa, los oficiales asfixian a su prisionero con un cinturón, sometiéndolo a un mecanismo de tortura premoderno, que demuestra la barbarie del poder estatal. En segundo lugar, Plutarco experimenta una suerte de cambio de conciencia en la cárcel que lo conecta con su hijo: se trata de la empatía de estar preso y darse cuenta del peligro que corre Luciano encarcelado en Managua. Pese a todas las diferencias ideológicas que los separan, Plutarco decide hipotecar un preciado terreno que había comprado como inversión para poder viajar a la capital y negociar la libertad de su hijo. Para ello, recurre a la escritura como herramienta de solicitud oficial y comienza la ardua tarea de redactar una carta:

tachada, reescrita, meditada, desechada, relevada hasta la última posibilidad de concretar lo que en sus visos de carta abierta debería contener la mágica apelación de una plegaria elevada al «excelentísimo señor», tachado y corregido tantas veces como necesitó para transformarse en «magnánimo señor». (pp. 412-413)

Por una parte, esta carta, reescrita una y otra vez, evoca el último gesto desesperado del padre ante el poder del dictador, quien impide la articulación del lenguaje escrito; y por otra parte, guarda la voz del subalterno, cuyo discurso simbólicamente es autocensurado. Finalmente, todo su esfuerzo y preocupación resultan en vano, ya que muere Luciano y la carta pasa a ser un documento sin sentido. La narración tampoco procura de reproducirla.

La tensión entre escritura y oralidad es un tema recurrente en Trágame tierra (1971) manifiesta directamente en los apartados donde aparece el "pueta descalzo". Estas secciones, siempre indicadas con letras en cursivas, adoptan la forma de un flujo de conciencia del pueblo, el que como colectivo lo apoda así porque con "una simple vocal alterada y el sustantivo quedó despojado de su pretensión, de la calidad de título de volador autorizado por nosotros para retratar dimensiones trágicas o mágicas de nuestros actos" (1971, p. 9). Su sobrenombre hace un claro guiño al habla vernácula, estableciendo su lugar en los márgenes de la esfera letrada, aunque sabe escribir y utiliza una pizarra de segunda mano para redactar poemas y pensamientos. Estos textos son materialmente frágiles, capaces de borrarse en cualquier momento, hasta con "un poco de sudor escurrido de la frente" (1971, p. 10). Se 
trata de una escritura desordenada, tanto en el contenido como en la forma de sus letras ("desiguales que trotan sobre líneas quebradas", 1971, p. 10), pero construye un espacio para registrar la memoria del pueblo, evidente en los dichos populares que transcribe y "todo lo que no se recuerda" (1971, p. 12); de manera que guarda elementos de una voz popular. Al respecto, Martin Lienhard (1992) señala que las cartas de reclamo escritas por dirigentes indígenas a autoridades coloniales constituyen el primer medio de escritura por el cual:

los depositarios de la memoria y de la conciencia colectivas dejan de ser sempiternos 'informantes' o los redactores de escritos al estilo europeo para convertirse en los autores, materiales o al menos intelectuales, de un texto propio en el sentido cabal de la palabra, en sujetos de una práctica literaria radicalmente nueva. (p. 59)

El "pueta descalzo" no es representante de un grupo indígena, pero pertenece a una clase subalternizada por su situación económica y la marginalización de la región donde vive. Pese a ello, su papel como "pueta" le permite revelar verdades ignoradas por los demás, escondidas entre chismes y trabalenguas, aunque generalmente asume el papel de bufón, una idea elocuentemente expresada en la siguiente frase: "Que me peguen otra vez por decir lo que dicen que no naci para decir" (1971, p. 140).

La presencia subyacente de este personaje a lo largo de la novela funciona como una operación transculturadora a través de la estructuración literaria, tanto por el carácter fragmentario de la voz como por el flujo de conciencia que representa ciertas fórmulas orales. El mismo Chávez Alfaro ha comentado que el personaje "Trata de reunir todos los atributos del coro" (citado por García 1970, p. 59), pero más que un coro de la Antigüedad clásica, el lenguaje del "pueta" responde a la realidad lingüística de la región retratada: por eso repite dichos populares, junta palabras que en el castellano estándar deben estar separadas ("nosesí", "quiensabe" o "Diosmiomilindo"). Incluso reproduce ciertos prejuicios y discriminaciones (en particular con Víctor por ser negro y homosexual) que sugieren los problemas de integración racial entre personas de una misma clase social. De esta manera, el "pueta descalzo" de Chávez Alfaro no es tan disímil a la función transculturadora que Rama identifica en las comadres pueblerinas de Juan Rulfo en Pedro Páramo (2007, p. 52). Cabe señalar que el lenguaje del "pueta" dista de una representación caricaturesca; al contrario, se abre hacia una significación compleja que mezcla archivos culturales populares con un amplio registro de la lengua española.

La evocación de una tradición oral no es exclusiva tarea del "pueta" y adquiere un papel importante en otros personajes y eventos de la novela. Es así con un breve recuento de la fundación mítica del país, que se relata como un recuerdo de 
Plutarco. Cada suceso del encuentro entre conquistadores españoles y Nicarao, un cacique indígena a quien se le atribuye el nombre del país, está parcelado por las palabras "Y oyó", que marca un pulso de la memoria y evoca el traspaso oral de la historia (1971, pp. 215-219). Sin embargo, recrea una visión idealizada del indígena que corre el riesgo de asociarlo con un pasado mítico, carente de potencia política actual. La ausencia del sujeto indígena contemporáneo es problemática, sobre todo para la región caribeña, donde gran parte de la población pertenece al pueblo miskito, siendo un grupo cultural que quedaría fuera del discurso transcultural de la novela.

\section{A modo de conclusión}

Trágame tierra (1971) es tanto una historia de las diferencias generacionales como lo es de la transculturación, de las culturas en procesos de contacto y bajo presiones de la modernización estatal. La muerte de Luciano y César, representantes de una generación que busca transformar la sociedad, puede significar el fracaso del intento revolucionario y del proyecto transculturador. Pero también puede leerse como un martirio, con sus respectivos impactos políticos por las causas que defendían los jóvenes, dialogando en cierto sentido con el legado de Sandino, cuya muerte desprendió la leyenda del revolucionario en el imaginario nacional. Como recuerda el "pueta descalzo" en el funeral de los jóvenes, fueron los agentes del Estado quienes mataron a ambos "por andar creyendo" (1971, p. 418), lo que deja en claro el peligro de pensar fuera del orden hegemónico estatal.

La elaboración teórica de Rama (2007) permite ver las distintas fuerzas culturales y políticas que impactan la producción literaria latinoamericana a la luz de los procesos modernizadores, validando los modos en que los escritores pertenecientes a sectores vulnerables han sido capaces de apropiarse de técnicas modernas y conservar elementos determinantes de sus culturas. Su conceptualización me ha sido útil para reflexionar sobre la novela de Chávez Alfaro, identificando al menos la presencia de una de las operaciones transculturadoras. Trágame tierra (1971) quizás no construya una lengua literaria ni un "pensar mítico" de la costa caribeña nicaragüense, pero sí inscribe la diferencia cultural de una región históricamente marginada en el imaginario nacional. Así, Chávez Alfaro introduce una visión más totalizadora del país que integra posibles subjetividades nuevas, cuestionando los relatos únicos sobre la experiencia nacional y la memoria de resistencia contra la dictadura somocista. Se puede interpretar este proyecto narrativo como transculturador, pero no promueve una visión tan armónica de la simbiosis cultural como lo transmite Rama (2007), quien reproduce cierto tono festivo inaugurado por Ortiz (1987) en torno al concepto. Como recuerda esta novela, las transformaciones culturales a partir de distintas fuentes siempre son conflictivas. Por lo tanto, resulta insuficiente descartar como cosmopolitas o poco 
auténticas las obras que no cumplen a pie de la letra con el esquema de Rama (2007). Desde una perspectiva actual, quizás tenga más sentido formar un nuevo canon de transculturación narrativa que integre obras que van más allá de los factores culturales europeos e indígenas, respondiendo a los conflictos surgidos de los escenarios urbanos, las variadas poblaciones afrodescendientes o las migraciones contemporáneas en América Latina.

\section{Referencias}

Addis, M. K. (2008). In memoriam: Lizandro Chávez Alfaro. Revista Iberoamericana, 74 (222), 283-285.

Bosch, J. (2009). De Cristóbal Colón a Fidel Castro. El Caribe frontera imperial. (Primera edición, 1970). México, D.F.: H. Cámara de Diputados, LX Legislatura; Embajada de la República Dominicana en Méxica; Miguel Ángel Porrúa.

Bolívar, S. (2009). Doctrina del libertador. Caracas: Biblioteca Ayacucho.

Chávez Alfaro, L. (1971). Trágame tierra. (Primera edición, 1969). La Habana: Casa de las Américas.

Chávez Alfaro, L. (1981). "Identidad y resistencia del 'criollo' en Nicaragua”. Cahiers du monde hispanique et luso-brésilien 36, 87-97. Extraído de http://www.jstor.org/stable/40852691

Delgado, L. (2011). El Caribe nicaragüense en textos de la literatura nacional moderna: de la civilización protectorista a la mulatidad global. América Latina Hoy, 58, 63-80. Extraído de http://revistas.usal.es/index.php/1130-2887/ article/viewFile/8506/8597

Delgado, L. (2013/2014). La memoria travestida: Caribe, estética e historia en Trágame tierra de Lizandro Chávez Alfaro. Istmo. Revista virtual de estudios literarios y culturales centroamericanos, 27-28, 1-14. Extraído de http://istmo.denison.edu/n27-28/articulos/03_delgado_leonel_form.pdf

Fraginals, M. M. (1980). En torno a la identidad cultural en el Caribe insular. Casa de las Américas (118), 42-47.

García F., M. (1970). Lizandro Chávez Alfaro. Entrevista con el Escritor. Encuentro: Revista Académica de la Universidad Centroamericana, (11), 59-62. Extraído de http://repositorio.uca.edu.ni/2310/1/Lizando\%20Ch\%C3\%A$1 \mathrm{vez} \% 20 \mathrm{Alfaro} . \mathrm{pdf}$

Gilman, C. (2003). Entre la pluma y el fusil. Debates y dilemas del escritor revolucionario en América Latina. Buenos Aires: Siglo Veintiuno Editores. 
Lienhard, M. (1992). La voz y su huella. Escritura y conflicto étnico-cultural en América Latina 1492-1988. (3ra edición revisada y aumentada). Lima: Editorial Horizonte.

Mackenbach, W. (2002). Representaciones del Caribe en la narrativa centroamericana contemporánea entre una perspectiva exterior y una perspectiva interior. Revista Reflexiones, 82(2), 113-124.

Ortiz, F. (1987). Contrapunteo cubano del tabaco y el azúcar. (Primera edición, 1940). Caracas: Biblioteca Ayacucho.

Palacios, N. (1991). La novela nicaragüense en el siglo XX. Revista Iberoamericana, 57 (157), 1019-1029.

Quijano, A. (2000). Colonialidad del poder, eurocentrismo y América Latina. La colonialidad del saber: eurocentrismo y ciencias sociales. Perspectivas Latinoamericanas. Edgardo Lander (comp.). Buenos Aires: CLACSO, Consejo Latinoamericano de Ciencias Sociales, 201-246.

Rama, Á. (2007). Transculturación narrativa en América Latina. (Primera edición, 1982). Buenos Aires: Ediciones El Andariego.

Ramírez, S. (Ed.) (1973). Antología del cuento centroamericano. (Tomo I). San José, Costa Rica: Editorial Universitaria Centroamericana (EDUCA).

Ríos Quesada, V. (2016). De monstruos, presas de cacería y presos en la novela Trágame tierra de Lizandro Chávez. Filología y Lingüística de la Universidad de Costa Rica, 42, 195-208.

Rodríguez, I. (1985). Trágame tierra: una narrativa consistente. Casa de las Américas (150), 79-89.

Sollis, P. (1989). The Atlantic Coast of Nicaragua: Development and Autonomy. Journal of Latin American Studies, 21(3), 481-520. 